\title{
Social Design: Design Actions Facing the Perspective of Humanistic Research
}

\author{
Yunqi $\mathrm{Li}^{1, *}$ Yuxin $\mathrm{Ma}^{2}$
}

${ }^{1}$ Fuzhou University of International Studies and Trade, Fuzhou, Fujian, China

${ }^{2}$ Xiamen Academy of Arts and Design, Fuzhou University, Fuzhou, Fujian, China

*Corresponding author. Email: 494769780@qq.com

\begin{abstract}
The origin of social design could be traced back to Beuys's "social sculpture" concept. Based on the definition of "social design", this paper analyzes the practical ability of "social design" in solving social problems by using "cultural creativity" and "life aesthetics", "cultural capital" and "field work" as evaluation factors. Finally, the combination of "communication design" and "social design" forms a joint design force to promote social progress.
\end{abstract}

Keywords: social design, design action, space design, communication design, design responsibility

\section{INTRODUCTION}

American design history researcher Victor Margolin once said: "The designer's responsibility is to create some form to interpret material or non-material products, and to solve problems while making contribution to the social welfare." A similar view can also be found in Victor Papanek's view about "Essence of Design", which is written in his own book, Design for the Real World in 1971. He said, "Design is the conscious and intuitive effort to impose meaningful order $^{1} . "$ Both of their views emphasize the role and responsibility of designers in our society, and the belief that the ethics of design, and social order are the basic principles of social design.

\section{SOCIAL DESIGN: A DESIGN ACTION} DIFFERENTIATING BETWEEN "CONCEPT" AND "SOCIAL INNOVATION"

Compared with the "conceptual speculation" or "social innovation" in the design in a parallel viewing field of view, the "conceptual design" is based on a fictitious model for scrutiny in the local field of different view. On the other hand, design actions about "social innovation" often consider social needs as a driving factor. Compared with the former one, "social design" is more willing to choose to do experiments and speculation in a real social circumstance. Its premise is true, emphasizing the "presence" of design; while separated from the latter's potential market economy orientation, "social design" obviously contains more diversity and inclusiveness that can be accommodated

\footnotetext{
Victor Papanek. Design for the Real Word [M]. Chicago: Academy Chicago Publishers, 2013:4.
}

in the field of humanistic research, by which it can shape the cultural paradigm and lifestyle under different space-time backgrounds, so that "social design" can be described in terms of a social value.

Moreover, "social design" can be traced back to the concept of "social sculpture" proposed by contemporary artist Beuys in the 1970s, which emphasizes the power of art to shape society through life aesthetics. Different from the potential social orientation of art, "design" an emerging discipline established after the Industrial Revolution, has shown the characteristics of being intertwined with society from the beginning. Modern society itself is also a "designed" composite carrier, which contribute by intricate relationships between individuals, individual and community. The concept of "design" contains a special social and cultural phenomenon. Tracing back to the beginning of "design history", British design historian Pevsner said in his book Pioneers of Modern Design: "The design ideas advocated by Morris in The Arts and Crafts Movement have become the initial awakening of modern design. Morris deeply feels that the transformative forces characterized by machines and industrialization will push aesthetics to the abyss of morality. ${ }^{2 "}$ Therefore, we can also see the close relationship between the development of design history and social ethics. As a design action for design subject itself to accept sociological research, "social design", must also include a kind of research thinking that can face the historical, cultural and social meanings, more than cliches such as "form" and "function", "concept" and "innovation" or other one-way narration in dualism.

\footnotetext{
Nicholas Pevsner. Pioneers of Modern Design [M]. Zhejiang people's fine arts Press, 2019.
} 


\section{PONDERING OVER HUMANISTIC PERSPECTIVES IN SPACE-TIME DIMENSION: FROM CREATING OF CULTURE TO FORGETTING OF LIFE AESTHETICS}

Cities are often regarded as a community for cultural "containers". As a result, social issues such as globalization, poverty, social isolation, and environmental degradation that urban spaces face are endless. Mumford believes: "Cities are the organs of social activities, all-inclusive cultures exchange, accumulate and inherit here. The symbiosis of cities and cultures, the huge and vast retention of history is one of the greatest values of megalopolis. ${ }^{3}$ "Therefore, when globalization has completed the modern cities, "culture" has become a new growth for urban renaissance. The power of design action involved in the "urban cultural revival" also generated tremendous energy. In recent years, the international industry association every two years will be named the world design capital, Taipei city is to "culture" as an opportunity to promote urban renewal process, relying on the interdisciplinary design thinking direction, by city distribution in numerous cultural creative park design, realized by "culture" Renaissance city spatial transformation, which won the 2016 "design it all" in the world. Therefore, Taipei is a representative city whose "urban cultural attribute" is transformed into "urban cultural capital". Due to the success of Taipei's urban cultural shaping, visual concepts such as "cultural creative industries", "cultural industries", "creative industries" and even "creative cities" have been imported and spread rapidly, becoming a research object for large and medium-sized cities in China to follow. The vocabulary such as "culture", "creativity", "aesthetics", "style" also became popular among the supporters from every community.

To some extent, the excessive consumption of culture has stimulated the intervention of design, and the revival of urban culture has evolved into a new round of shaping "globalized homogeneous space". Taking the urban space of Fujian Province as an example, Fuzhou is an ancient city with a history of more than 2,200 years. Three Lanes and Seven Alleys area in the center of this city was originally the inner city area where elites in Fuzhou gathered. In the late Qing Dynasty, Wan Guorui's inscribed a couplet in the Nanhou Street archway in Three Lanes and Seven Alleys which as titled: "I went to the Book Market and saw many things I haven't Seen before, which makes me jubilant." This poet from Guangzhou city described Nanhou Street in Three Lanes and Seven Alleys as a concentration of Fuzhou ancient bookstores, where people linger on old books and the celebrity calligraphy and painting of the past dynasties. However, as the

Mumford. Urban development history: origin, evolution and prospect $[\mathrm{M}]$. Beijing: China Building Industry Press. earliest batch of "historical and cultural cities" selected by the country, the urban cultural capital of also forced Three Lanes and Seven Alleys from the gathering place of literati and elites to be a striking material consumption space constituted by growing service industry and material wealth. The cultural value of Three Lanes and Seven Alleys also had to be operated by the commercial capital as a cultural symbolic capital of the "Ming and Qing Ancient Architecture Museum" and the "living fossil" of the city's Lifang system ("Fig. $1 ")$. In addition, the urban spaces outside the "inner city", such as the Chinese and foreign chamber of commerce, church consulate and other prosperous area that flourished in modern times in Nantai Shangxiahang and Cangqian Yantai Mountain in Fuzhou, now appear as "commodity culture" as well. While the regional culture and architectural culture are restored and protected, the internal spaces which connecting to the living memory and the space memory are transformed into homogeneous commercial investment place. The self-identity and self-expression of urban residents was erased together with their memory about the original city by the ferocious urban reconstruction ("Fig. 2").

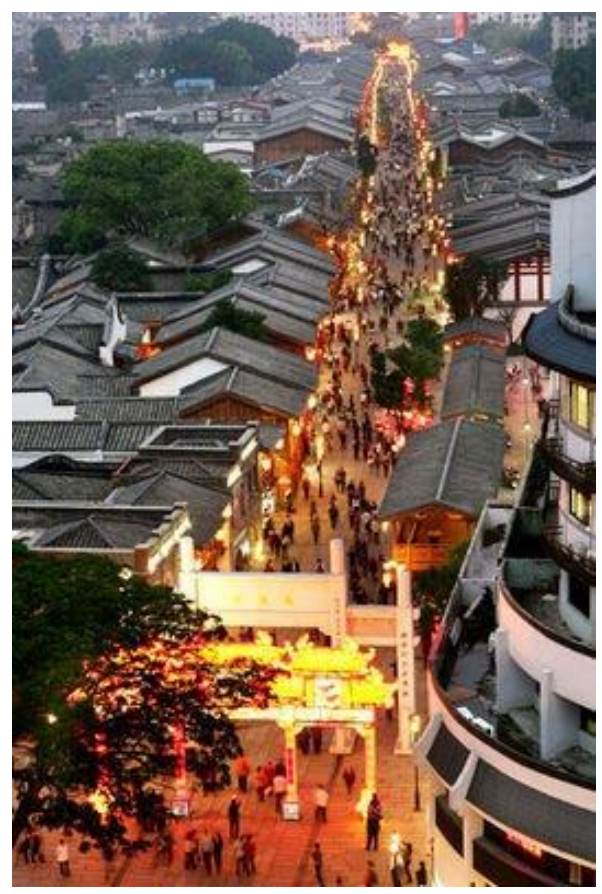

Fig. 1. Current situation of Three Lanes and Seven Alleys. 


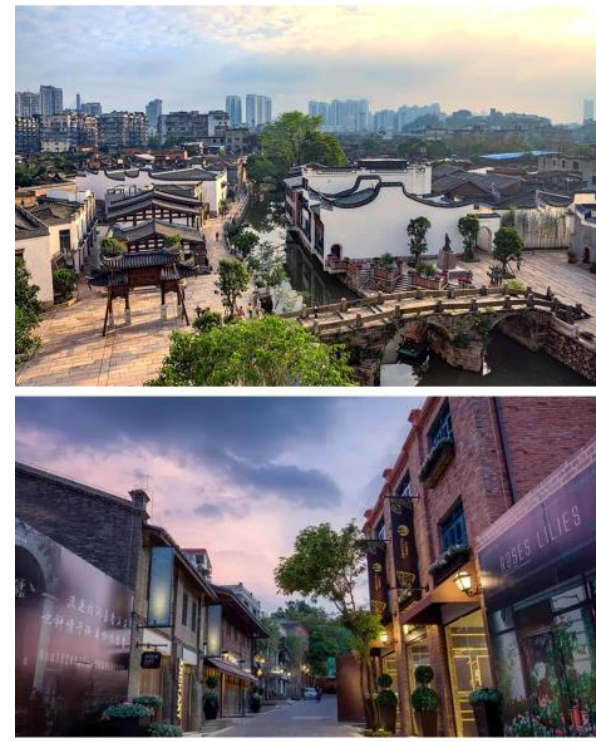

Fig. 2. Status quo of cultural space transformation in Fuzhou.

\section{DESIGN ACTION BACK TO PRACTICE: FROM CULTURAL CAPITAL TO FIELD WORK}

The expansion of cultural capital and the rapid advancement of visual culture not only highlight the tremendous remolding of the working capital which cities are pursuing to the city space, but also reflect that the promotion of design to society should not stop at visual innovation, but act as social responsibility. Especially for the design action of space, this can give prominence to the social significance of space design in the intersection with sociology. It is because that the orientation of society has remarkable spatial feature. Taiwan Space Architect Mr. Lai Bowei uses handpainted, photo processing and computer modeling to present images of 108 forms of Taipei temples that adapt to urban changes ("Fig. 3") in his book Observation of Parasitic Temples-Street Temples in the Cracks of Taiwan's Cities, Adapting to Social Changes. These temples may be interspersed deep in the streets and neighborhoods, or hidden under the overpass. Furthermore, even "elevator temples" and "parking temples" appeared. Lai's book explains that these temples are both a place of religious belief and a meeting place for social life, which not only expands the resilience and transformation of Taiwan's urban society, but also reveals the unique character of "gentle, modest and courteous" in Taiwan society ${ }^{4}$. Therefore, the "parasitic temple" uses a typological analysis method to participate in the spatial phenomenon hidden beyond the reach of the Taipei urban planning. The intention is not to completely solve the problem or

Lai Bo-wei, Observation of Parasitic Temples-Street Temples in the Cracks of Taiwan's Cities, a guide to the common people's space adapting to social changes [M] Taipei: Savage Culture Press, 2017, 10. change the current status of design creation, but to form a platform which allows people to discuss social phenomena sustainably. More importantly, the exploration of image typology represents the authenticity of the content research emphasized by social design. It means to comprehend the design responsibilities in the "social process" and to use the action research into the "field work" to reflect the social awareness and social responsibility of design. The art history researcher Alois Riegl believes that: "The content of the image is different from the content of art. The former's function is to awaken the specific concept in the viewer's heart, so it is an external function similar to architecture and decorative artwork. The function of art is to make the object a sense of relief in the viewer's heart ${ }^{5}$."

Similar to the field work of Mr. Lai Bowei's "parasitic temple", Mr. Huang Heshan, who was still studying in Qinghua Academy in 2016, defined the theme of his graduation design as "wild design". Affected by small advertisements in life, Huang Heshan walked Throughout the fringe of Beijing, Guangzhou and other cities, the design of ordinary people in daily life was recorded and thoroughly explored and considered in the form of images, and finally compiled into a book, which explained the concept of contemporary artist Boyce's "social sculpture" Extended explanation: Everyone is an artist. For example, small advertisements scattered on several mottled walls ("Fig. 4") have evolved into a "capital competition" for military strategists. For many ordinary retailers who do not have the opportunity to promote their products through Internet TV and other platforms, it is necessary to use all means "stand out" from the densely covered walls. Therefore, the folk "wild design", like the temples parasitic in various "transformation" in the Taipei city, is often a work squeezed out between the huge social needs and the extremely limited social conditions. Therefore, how to use detailed field work attitudes to understand more profound social problems in different social phenomena, even if the design work does not give these seemingly "wild" works a more refined aesthetic creation, but by means of iconography, Typology, etc., these scenes are themselves the dissemination of aesthetics and narrative carried out by the design language. The design work on the one hand shows a kind of vigor and vitality, on the other hand, it also achieves pragmatically the task of promoting social improvement or innovation.
Edgar Wynder, Yang Siliang. Warburg's concept of "cultural science" and its significance to aesthetics [J]. New Fine Arts, 2008, 39 (03): 15-27 + 133 


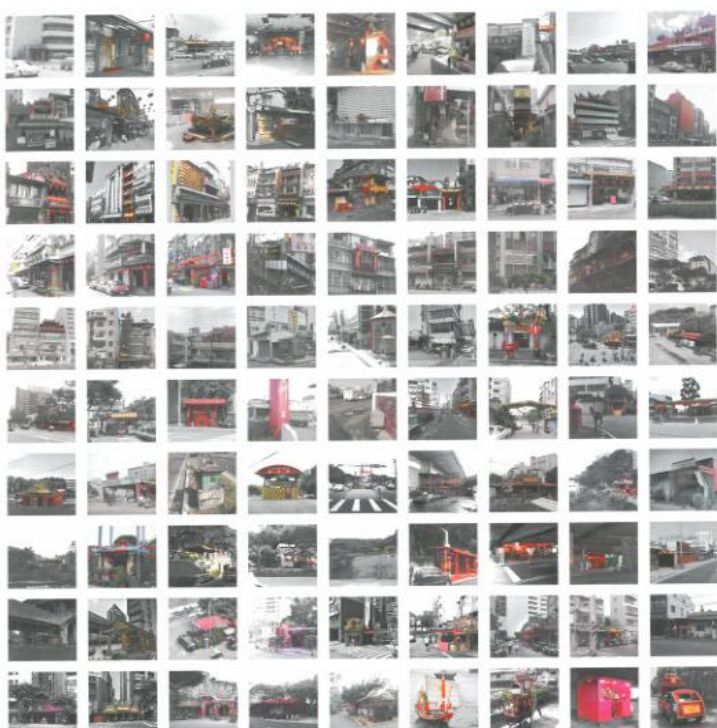

Fig. 3. A typological analysis of the current situation of temples in Taipei.

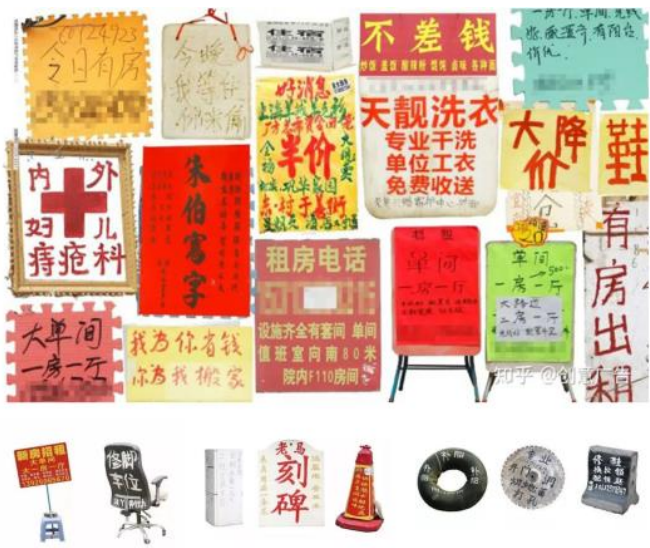

Fig. 4. "Little ads" designed by the wild.

\section{V. "SOCIAL DESIGN" IN COMMUNICATION DESIGN}

Whether the "parasitic temple" or the "wild design", their designers interpret it by means of images eventually. Nowadays, communication design utilizes design energy to explain or solve social issues. In terms of the timeliness of communication and the value of concepts, the prior significance to combine communication design and social design is to form a joint and invisible force to promote social progress. The Red Dot Design Award is one of the most influential ones in the world's well-known design competitions. The works participating in the Red Dot Design Award each year also contain many practical examples of the combination of communication design and social design. For instance, the discussion on sustainable design is an extension of the discussion on environmentally sustainable design in recent years. It does not stop at environmental issues, but refers to the concept of sustainable circulation that makes the best use of everything, or social design that makes the system more perfect. One of the winning works of the Red Dot Communication Design Awards in 2018, "SOS" ("Fig. 5"), the design concept is to express the urgency of reusing waste paper through the title "SOS" and the classic painting "Scream" by the expressionist painter Munch. The implication of it is to call on more designers to take part in the design creation related to "sustainable design". It also indicated that design aesthetics can exist in any material-although it has been recycled many times.

In addition, "curation" is also a method communication design use to exhibit "social design". Any social practice need to combine with exhibition. The cross-domain linkage between curation and the visual communication design of Tainan Old barbershop B \& B is an example of communication design involved in social design. The designer found that the old-school barbershop can be a symbol of gentleman style. With the rise of the modern beauty salon, some of these barbershops hide eroticism in order to survive, so they have to post the word "pure" to prove their innocence, and the word "pure" accidentally became the cultural symbol of traditional barbershop in Taiwan ("Fig. 6"). Moreover, because of the unique historical background of Taiwan, these old-school barbershops have produced a mixed culture of China, Japan, and Europe. Therefore, the traditional barbershops in Taiwan contain rich and diverse stories, from urban evolution to artifact history. In order to present a better environment for the viewers to absorb the barbershops hidden in the alleys of the city, and to experience the rise and fall of the past half century, the designer takes the role of curator and abandons the traditional venue arrangement method. Instead, uses a booklet that introduces the traditional barbershop of Tainan City as a means of propaganda through visual communication design, which is free of time and space limitations ("Fig 7"). Finally, uses an old barbershop as a "history storyteller". To emphasize the features of the furniture in it, the designer allows the visitors to experience the feeling of "sleeping in the barber chair" ("Fig. 8"). The designer created a brand-new experience and service with an "exhibition" manual. More importantly, the brochure also contains an introduction to the urban culture of Tainan City. There is introductory QR-code around each old barbershop waiting to be scanned. Visitors can also get to know an old settlement of Tainan through the traditional barbershop ${ }^{6}$.

Li Yunqi, Wu Shaoping. Translation of narrative expression of contemporary art curatorial exhibition in the design of homestay [J]. Decoration, 2008, 10: 106-108. 


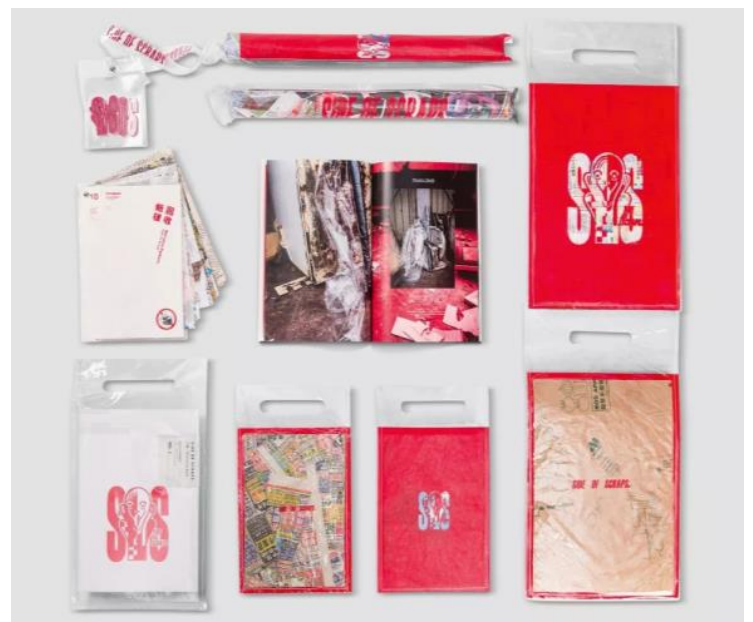

Fig. 5. Red dot communication design award winners: "SOS".

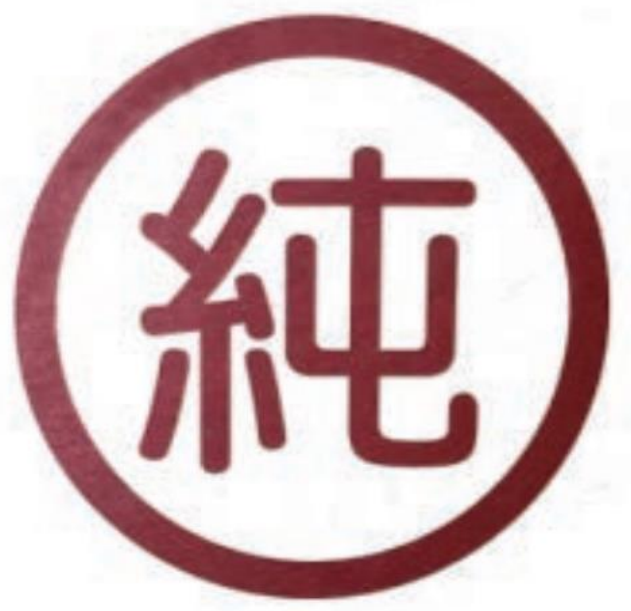

Fig. 6. The cultural symbol of traditional barbershop in Tainan.

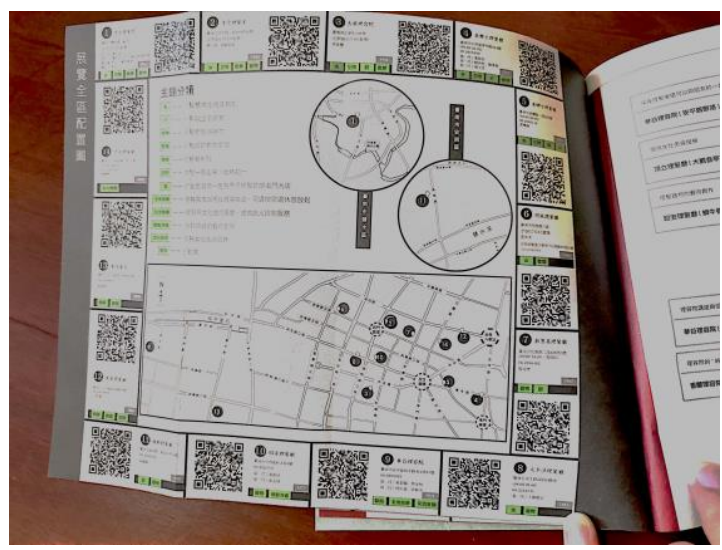

Fig. 7. Exhibition brochure.

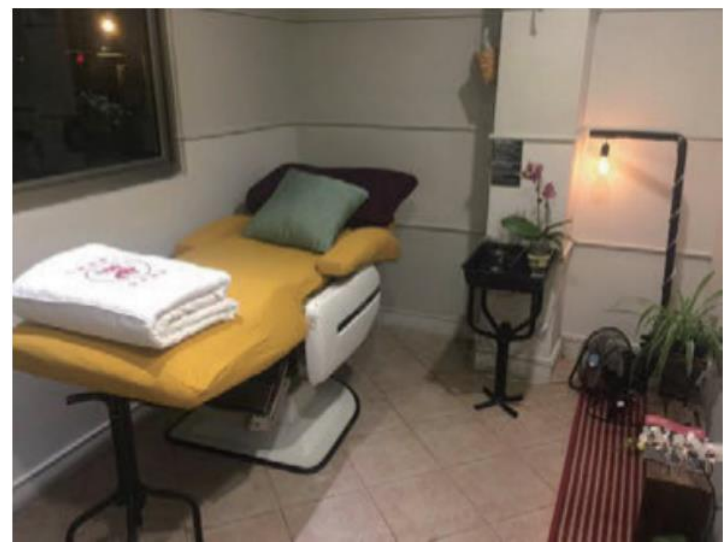

Fig. 8. "Accommodation chair/bed" in the bedroom of a home stay barbershop in Tainan.

\section{CONCLUSION}

Social responsibility and social consciousness have always been the hot topics in the field of humanistic research. It is also a field in design activities and design education that requires continuous discussion and practice. When the construction of the aesthetic system cannot solve the complicated social problems, social design comes forward. As a new design form, social design means that the design should include the research of sociology while design has problem with self-identity between art and engineering. From this perspective, the concept of social design in contemporary design is also an important component of design action because of its practical significance. From the beginning of design, its attributes determine when it's shaping a product or space, it will definitely meet the real condition in society, and thus as a form of sociological research and continue to produce value that convey social emotions.

\section{References}

[1] Victor Papanek. Design for the Real Word [M]. Chicago: Academy Chicago Publishers, 2013:4

[2] Nicholas Pevsner. Pioneers of Modern Design [M]. Zhejiang people's fine arts Press, 2019.

[3] Mumford. Urban development history: origin, evolution and prospect $[\mathrm{M}]$. Beijing: China building industry press.

[4] Lai Bowei, Observation of Parasitic Temples-Street Temples in the Cracks of Taiwan's Cities, a guide to the common people's space adapting to social changes $[\mathrm{M}]$ Taipei: savage culture press, 2017, 10.

[5] Edgar Wynder, Yang Siliang. Warburg's concept of "cultural science" and its significance to aesthetics [J]. New fine arts, 2008, 39 (03): $15-27+133$

[6] Li Yunqi, Wu Shaoping. Translation of narrative expression of contemporary art curatorial exhibition in the design of homestay [J]. Decoration, 2008, 10: 106-108. 